\title{
LARANGAN HIBURAN MALAM DI KECAMATAN KARANG BARU KABUPATEN ACEH TAMIANG PASCA SURAT EDARAN FORKOMPIMDA DALAM TINJAUAN MAQASHID SYARI'AH
}

\author{
Kahar Muzakir \\ Sekolah Tinggi Agama Islam Aceh Tamiang (STAI-AT) \\ kaharmuzakir430@gmail.com
}

\begin{abstract}
One of the night entertainment that is loved is the keyboard, there are many violations of the Shari'ah from the keyboard. Circular of Forkompimda regarding nightlife in Aceh Tamiang District: it is explained that night entertainment (keyboard/band and the like) is prohibited in Aceh Tamiang District except under government supervision. This study aims to see the condition of night entertainment in the district. New Coral District. Aceh Tamiang, the implementation of night entertainment as regulated in the Forkompimda Aceh Tamiang Circular, as well as the Sharia Maqashid Review of the ban on night entertainment after the Forkompimda Aceh Tamiang Circular. The findings in the study revealed the state of night entertainment in the district. Karang Baru before the circular letter often had a keyboard, this custom has been going on for a relatively long time and is held until late at night. The involvement of the Satpol $\mathrm{PP}$ and $\mathrm{WH}$ to take firm action if there are violations is a mandate from the Forkompimda circular letter. There are five main elements that must be maintained and realized at the level of Maqashid Sharia, namely religion, soul, mind, lineage, and property. So in the prohibition of night entertainment, the thing to be maintained is to maintain the religion of Islam, then maintain the mind so that it is not damaged by negative things such as the influence of liquor, marijuana, shabu-shabu and so on which can damage the working system of the brain which results in loss of common sense in acting. . Then take care of offspring so that adultery does not occur during keyboard events, especially if it arrives late at night.
\end{abstract}

Keywords: Forkompimda Circular Letter, Maqashid Syariah, Night Entertainment

\begin{abstract}
Abstrak
Salah satu hiburan malam yang diganderungi yaitu keyboard, banyak terjadi pelanggaran syari'at dari adanya keyboard. Surat edaran Forkompimda tentang hiburan malam dalam wilayah Kabupaten Aceh Tamiang: dijelaskan bahwa
\end{abstract}


hiburan malam (keyboard/ band dan sejenisnya) dilarang di Kabupaten Aceh Tamiang kecuali dalam pengawasan pemerintah. Studi ini bertujuan untuk melihat kondisi hiburan malam di Kec. Karang Baru Kab. Aceh Tamiang, pelaksanaan hiburan malam yang diatur dalam Surat Edaran Forkompimda Aceh Tamiang, serta Tinjauan Maqashid Syariah terhadap larangan hiburan malam pasca Surat Edaran Forkompimda Aceh Tamiang. Temuan dalam studi diketahui keadaan hiburan malam di Kec. Karang Baru sebelum adanya surat edaran sering terdapat keyboard, kebiasaan tersebut telah berlangsung dalam kurun waktu yang relatif lama dan diadakan hingga larut malam. Keterlibatan pihak Satpol PP dan WH untuk menindak tegas jika terdapat pelanggaran merupakan amanat dari surat edaran Forkompimda. Ada lima unsur pokok yang harus di pelihara dan diwujudkan dalam tataran Maqashid Syariah yaitu agama, jiwa, akal, keturunan, dan harta. Maka dalam pelarangan hiburan malam hal yang ingin dijaga yaitu memelihara agama Islam, kemudian memelihara akal agar tidak dirusak dengan hal negatif seperti pengaruh minuman keras, ganja, sabu-sabu dan lain sebagainya yang dapat merusak sistem kerja otak yang berakibat pada hilangnya akal sehat dalam bertindak. Kemudian memelihara keturunan agar tidak terjadi perzinaan ketika acara keyboard, terlebih jika sampai sampai larut malam.

Kata Kunci: Surat Edaran Forkompimda, Maqashid Syariah, Hiburan Malam.

\section{Pendahuluan}

Kabupaten Aceh Tamiang adalah salah satu Kabupaten yang berada di Provinsi Aceh. Kabupaten ini merupakan hasil pemekaran dari Kabupaten Aceh Timur dan terletak di perbatasan Aceh dengan Sumatera Utara. Kabupaten Aceh Tamiang berada di jalur timur Sumatera Utara yang letaknya sangat strategis dan hanya berjarak lebih kurang $136 \mathrm{~km}$ dari kota Medan. Sehingga akses serta harga barang di kawasan ini relatif lebih murah daripada daerah Aceh lainnya (Badan Pusat Statistik Aceh Tamiang, 2018).

Kabupaten Aceh Tamiang memiliki dua belas kecamatan, salah satunya yaitu kecamatan Karang Baru. Karang Baru merupakan jantungnya Kabupaten Aceh Tamiang atau biasa dijuluki ibukota Aceh Tamiang. Hal ini dapat dilihat dari luasnya kecamatan Karang Baru dengan tiga puluh satu desa, serta berbagai intansi pemerintahan berada di Kecamatan Karang Baru dari mulai Kantor Bupati, Kantor DPRD dan lainnya. Dengan demikian selain letak yang berbatasan langsung dengan Sumatera Utara, letak yang strategis sebagai jantungnya Kabupaten Aceh Tamiang serta pusat kota dengan berbagai macam instansi pemerintahannya membuat kecamatan Karang Baru menjadi berkembang. Sedikit banyaknya mendapat pengaruh-pengaruh dari luar, misalnya berubahnya kebutuhan dan cara pandang masyarakat kecamatan Karang Baru dalam hal hiburan. Pada awalnya mereka berpendapat hiburan bisa didapatkan dengan cara berkumpul dengan temanteman atau melihat televisi saja. Namun, saat ini telah berubah pendapat bahwa hiburan itu didapatkan di tempat semestinya yaitu misalnya tempat keyboard, karaoke, bilyard, diskotik dan lainnya. 
Perubahan dan modernisasi yang dijadikan sebagai tonggak awal kemajuan zaman, telah memberikan pengaruh dan dampak pada berbagai aspek kehidupan dan kemanusian yang luar biasa pada abad ini. Modernisasi juga membawa dampak perubahan yang fundamental dalam berbagai bidang dan nilai kehidupan, yang tentunya akan memberi konsekuensi dan pengaruh bagi manusia sebagai komponen dalam kehidupan.

Hiburan ini juga dijadikan salah satu usaha yang dianggap menjanjikan dan berpotensial sehingga dapat meningkatkan perekonomian bagi pengusaha-pengusaha keyboard, karaoke dan lain-lain yang tentu saja didasarkan pada banyaknya peminat hiburan ini, khususnya kalangan remaja. Tempat hiburan ini dianggap sebagai tempat rekreasi alternatif setelah menyelesaikan kegiatan hariannya, dengan fasilitas yang lengkap sebagai hiburan memberikan pilihan bagi masyarakat untuk melepas penat dari rutinitas sehari-hari.

Salah satu hiburan malam yang sangat digandrungi baik kalangan remaja maupun dewasa yaitu keyboard. Hiburan ini biasanya sering dijumpai pada acara pesta pernikahan, perayaan malam pergantian tahun dan sebagainya. Dengan semakin banyaknya peminat keyboard ini, mengakibatkan banyaknya terjadi pelanggaran Syariat Islam.

Sehubungan dengan hal itu lahirlah Qanun Kabupaten Aceh Tamiang Nomor 11 Tahun 2008 tentang Izin dan Tata Cara Penyelenggaraan Hiburan. Dalam pasal 6 disebutkan mengenai tata cara memperoleh izin, yaitu dalam ayat 1 dikatakan bahwa setiap orang atau badan yang menyelenggarakan hiburan harus memperoleh izin dari Kepala Dinas Syariat Islam (Qanun Kabupaten Aceh Tamiang Nomor 11 Tahun 2008 tentang Izin dan Tata Cara Penyelenggaraan Hiburan, 2008). Selanjutnya dalam surat edaran FORKOMPIMDA/FORKOMPIMDA Plus dan intansi terkait tentang hiburan malam dalam wilayah Kabupaten Aceh Tamiang. Dijelaskan lebih rinci bahwa melarang hiburan malam (keyboard/band dan sejenisnya) di Kabupaten Aceh Tamiang kecuali dalam pengawasan pemerintah Kabupaten Aceh Tamiang. Tujuannya tidak lain adalah untuk menjauhkan dari hal-hal yang tidak diinginkan yang nantinya dapat melanggar Syariat Islam.

Salah satu ilmu yang terdapat dalam kajian fiqh yaitu Maqashid Syariah, yang berarti tujuan Allah dan RasulNya dalam merumuskan hukumhukum Islam. Tujuan itu dapat diketahui dalam ayat-ayat Alquran dan Sunnah Rasulullah sebagai alasan logis bagi rumusan suatu hukum yang berorientasi kepada kamshlahatan umat manusia (Efendi, 2008: 233). Apabila dipelajari secara seksama ketetapan Allah dan RasulNya yang terdapat di dalam Alquran dan Sunnah Rasul yang Shahih, kita dapat segera mengetahui tujuan hukum Islam. Seiring dirumuskan bahwa tujuan hukum Islam adalah kebahagiaan hidup manusia di dunia dan di akhirat kelak, dengan jalan mengambil segala yang bermanfaat dan mencegah atau menolak yang mudharat yaitu yang tidak berguna bagi hidup dan kehidupan (Mukhibad, 2019) 
Dengan kata lain, tujuan hukum Islam adalah kemashlahatan hidup manusia, baik rohani maupun jasmani, individual dan sosial. Kemashlahatan itu tidak hanya untuk kehidupan dunia ini saja, tetapi juga untuk kehidupan yang kekal di akhirat kelak. Eva Muzlifah dalam tulisannya menyampaikan bahwa Abu Ishaq Al-Shatibi merumuskan lima tujuan hukum Islam, yakni (Muzlifah, 2013: 79):

1. Hifzh Ad-Din (memelihara Agama)

2. Hifzh An-Nafs ( memelihara Jiwa)

3. Hifzh Al-'Aql (memelihara Akal)

4. Hifzh An-Nasb (memelihara Keturunan)

5. Hifzh Al-Maal (memelihara Harta)

Berangkat dari permasalahan tersebut, penulis tertarik untuk mengkaji permasalahan tersebut, selanjutnya penulis ingin mengadakan penelitian secara ilmiah dengan mengangkat topik permasalahan tentang Larangan Hiburan Malam Dalam Tinjauan Maqashid Syariah Pasca Surat Edaran Forkompimda (Studi Kasus Kecamatan Karang Baru, Kabupaten Aceh Tamiang).

\section{Pembahasan}

1. Isi Surat Edaran Forkompimda

Maklumat Kesepakatan Bersama Forkompimda/Forkompimda Plus dan Instansi Terkait Tentang Hiburan Malam Dalam Wilayah Kabupaten Aceh Tamiang.

a. Jajaran Pemerintah Forkompimda/Forkompimda Plus dan Instansi Terkait Kabupaten Aceh Tamiang dengan ini menyatakan semangat dan tekad bersama untuk meniadakan dan atau melarang hiburan malam (Keyboard/Band dan sejenisnya) di Kabupaten Aceh Tamiang kecuali dalam pengawasan Pemerintah Kabupaten Aceh Tamiang.

b. Memberi Mandat kepada jajaran Kepolisian, TNI dan Satpol PP/WH Kabupaten Aceh Tamiang untuk mengawasi dan atau menindak tegas setiap masyarakat yang melanggar (Selebaran Surat Edaran yang dikeluarkan di Karang Baru, 2015).

2. Musik Dalam Islam

Permasalahan musik dan lagu merupakan permasalahan hangat yang banyak dibincangkan oleh para ulama. Ada hal-hal yang disepakati dan ada juga yang diperselisihkan oleh mereka. Para ulama sepakat bahwa nyanyian yang diharamkan adalah nyanyian yang mengandung keburukan, kefasikan, dan dorongan melakukan kemaksitan. Sebab nyanyian adalah ucapan, ucapan yang baik adalah baik dan ucapan yang buruk adalah buruk. Terlebih lagi jika ucapan yang mengandung keburukan tersebut berkumpul didalamnya sajak, irama, musik dan dorongan-dorongan kejahatan.

Sebagaimana para ulama juga sepakat bahwa nyanyian/nasyid yang fitrah tidak menggunakan alat musik dan tidak ada dorongan kejahatan, dilakukan dalam suasana bahagia yang dibolehkan oleh syara' seperti: walimah pernikahan, ketibaan orang yang datang dari perjalanan jauh, di 
saat hari raya adalah dibolehkan namun dengan syarat yang bernyanyi bukanlah wanita di hadapan non mahramnya.

Adapun nyanyian yang diiringi dengan musik tanpa ada dorongan kemaksiatan maka para ulama berbeda pendapat. Namun kami memilih pendapat yang mengatakan bahwa musik yang demikian itu dibolehkan berdasarkan tujuh dalil namun tetap dengan menjaga satu syarat. Ketujuh dalilnya adalah:

1. Masalah musik adalah masalah khilafiyah

Sebabnya adalah ketiadaan dalil yang jelas dan yang tegas menyatakan pengharamannya. Demikian yang dikatakan oleh Al Qadhi Abu Bakar bin al 'Arabi, Al Ghazzali, Ibnu al Nahwi, Ibnu Thahir. Bahkan Ibnu Hazam mengatakan: "Setiap dalil yang diriwayatkan tentang pengharaman nyanyian adalah bathil dan palsu".

Karena itu tidak layak bagi seorang muslim menuduh fasiq terhadap sebagian lainnya. Ini bukanlah masalah akidah atau ushuliyah, namun ini adalah masalah furu' dan khilafiyah yang tidak layak kita pungkiri. Sufyan alTsauri pernah mengatakan: "Jika kamu melihat seseorang yang melakukan amalan yang diperselisihkan oleh para ulama, dan kamu berpendapat lain, janganlah kamu melarangnya" (Al Ashbahani, 2004: 368).

2. Pada masa Nabi SAW pernah ada musik dan nyanyian

Di dalam Tafsir Al Jami' li Ahkam Al-Qur'an, Imam Al Qurthubi, mengatakan:

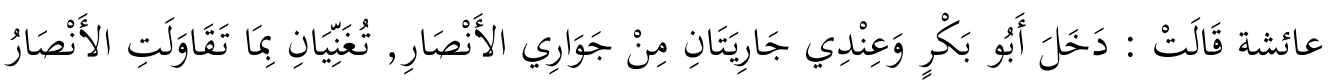

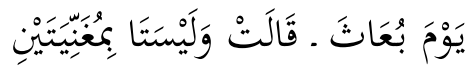

"Telah dipukul gendang di hadapan Nabi SAW ketika beliau tiba di Madinah. Abu Bakar bermaksud untuk menghalangi mereka. Rasulullah SAW bersabda: "Biarkanlah mereka wahai Abu Bakar agar orang Yahudi tahu bahwa agama kita sangat lapang”. Para wanita Anshar memukul gendang dan bersenandung: "Kami wanita dari Najjar, senang bertetangga dengan Muhammad".

Begitu pula dalam Shahih Al Bukhari dari Ummu Mukminin Aisyah ra bahwa Abu Bakar datang ke rumah Aisyah dan di waktu itu terdapat dua orang anak perempuan suasana masih di hari mina (hari Idul Adha) keduanya menyanyi dan memukul gendang dan Nabi SAW sedang menutup wajah beliau dengan pakaian. Abu Bakar menghardik keduanya. Lalu Rasulullah SAW membuka pakaian dari wajah beliau dan bersabda:ı

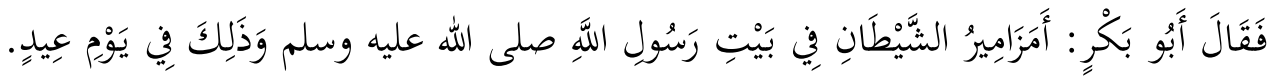

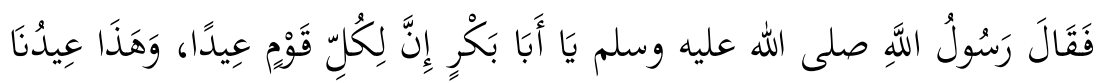


"Biarkanlah mereka berdua wahai Abu Bakar. Sesungguhnya ini adalah hari raya". (H.R. Al Bukhari).

3. Maqashid Syariah

1. Pengertian Maqashid Syariah

Untuk memahami tentang Maqashid Syariah perlu diketahui terlebih dahulu pengertiannya baik secara bahasa maupun secara istilah. Secara bahasa Maqashid Syariah merupakan gabungan dari dua kata, yaitu maqashid dan syariah. Menurut bahasa maqashid adalah bentuk jamak dari maqashid yang merupakan masdar dari kata , (Ibn Zakariyya, 1994: 891), yang dapat diartikan dengan makna "maksud" atau "tujuan". Sedangkan kata syariah, secara kebahasaan kata syariah pada dasarnya dipakai untuk sumber air yang dimaksudkan untuk diminum. Kemudian orang Arab memakai kata syariah untuk pengertian jalan yang lurus. Dengan kata lain maksudnya bahwa sumber air adalah jalan yang lurus yang membawa manusia pada kebaikan (Musolli, 2018).

Maslahah yang menjadi prinsip dalam Maqashid Syariah dengan memandang hubungannya dengan kelompok atau perorangan terbagi pada dua pembagian. Yaitu:

1. Maslahat Kulliyah, yaitu maslahat yang kembali kepada seluruh umat atau jemaah yang besar berupa kebaikan dan manfaat, seperti menjaga Negara dari musuh, menjaga umat dari perpecahan, menjaga agama dari kerusakan.

2. Maslahat al-Juz'iyyah al-Khashshah, yaitu maslahah perseorangan atau perseorangan yang sedikit, seperti pensyariatan dalam bidang muamalah, yaitu hubungan antara individu dengan individu yang lain (Rahmi, 2018).

Kemudian, apabila maslahah tersebut dipandang dari segi kekuatan yang timbul dari dirinya dan bekas yang dihasilkan, terbagi kepada tiga tingkatan, yaitu:

1. Dharuriyat

Maslahat Dharuriyat adalah sesuatu yang mesti ada dalam rangka melaksanakan kemaslahatan atau dengan kata lain bahwa Dharuriyat adalah kemaslahatan yang tergantung terhadap adanya maslahat tersebut kehidupan manusia pada agama dan dunianya. Yaitu dengan perkiraan apabila hal itu tidak ada, kemaslahatan dunia tidak akan terlaksana dan menjadi rusak dan binasa, dan di akhirat tidak mendapat kebahagiaan bahkan akan mendapatkan siksa.

Dalam bentuk Dharuriyat ini, ada lima prinsip yang harus dipelihara yaitu agama, jiwa, akal, keturunan dan harta. Hal ini diisyaratkan oleh Allah dalam firmannya pada Q.S Al-Mumthahanah (60): 12: 
"Hai Nabi, apabila datang kepadamu perempuan-perempuan yang beriman untuk Mengadakan janji setia, bahwa mereka tiada akan menyekutukan Allah, tidak akan mencuri, tidak akan berzina, tidak akan membunuh anak-anaknya, tidak akan berbuat dusta yang mereka ada-adakan antara tangan dan kaki mereka dan tidak akan mendurhakaimu dalam urusan yang baik, maka terimalah janji setia mereka dan mohonkanlah ampunan kepada Allah untuk mereka. Sesungguhnya Allah Maha Pengampun lagi Maha Penyayang." (Q.S. Al-Mumthahanah: 12) (Al-Qur'an dan Terjemahannya, n.d.).

Ayat ini tidak dikhususkan untuk perempuan yang mukmin saja. Rasulullah SAW juga mengambil bai'at dari laki-laki seumpama ayat yang diturunkan tentang perempuan-perempuan mukmin. Namun, tidak mustahil kelima bentuk Dharuriyat ini terjadi benturan antara yang satu dengan yang lainnya. Umpamanya, pada saat yang sama manusia dilarang meminum khamar karena memelihara akal, dan ia juga berkewajiban untuk memelihara jiwanya pada saat yang terpaksa, maka ia boleh minum khamar untuk bertahan hidup (Wira, 2001: 377).

2. Hajjiyat

Hajiyat adalah maslahah yang dikehendaki untuk memberi kelapangan dan menghilangkan kesulitan atau kesempitan bagi manusia. Sekiranya maslahah itu tidak ada atau hilang, maka kehidupan manusia menjadi sulit dan akan memberikan kesempitan bagi mukallaf, yang tidak sampai pada tingkat kerusakan, seperti pensyariatan rukhsah yang meringankan taklif dalam beribadah bagi mukallaf yang mendapat kesulitan seperti sakit dan dalam perjalanan (musafir). Mengenai hal ini, terdapat kaidah fiqh yang dapat dipakai sebagai penguat bagi kemaslahatan yang bersifat Hajiyat ini, yaitu: "Kebutuhan (hajat) menduduki posisi dharurat, baik yang bersifat umum maupun yang bersifat khusus" (al-Rahman, Imam Jalal al-Din Abd, n.d.: 62).

3. Tahsiniyat

Tahsiniyat adalah mengambil sesuatu kemaslahatan yang pantas dari hal yang bersifat keutamaan atau merupakan kebaikankebaikan menurut adat dengan menjauhi keadaan-keadaan yang menodai dan yang tidak disukai oleh akal sehat. Hal ini masuk dalam persoalan yang berupa penyempurnaan terhadap akhlak. Seperti menghilangkan najis dan menutup aurat dalam beribadah, memakai perhiasan dan melaksanakan ibadah-ibadah Sunah dalam mendekatkan diri kepada Allah dan lain sebagainnya. Pelaksanaan Maqashid Syariah yang bersifat Tahsiniyat ini dimaksudkan agar manusia dapat melakukan sesuatu yang terbaik untuk penyempurnaan terhadap pemeliharaan dari lima prinsip yang 
harus dipelihara, yaitu: agama, jiwa, akal, keturunan, dan harta. Salah satu kaidah fiqh yang dapat dipakai unruk pelaksanaan kemaslahatan ini, adalah kaidah yang berbunyi: "Dianjurkan untuk keluar dari perselisihan (sesuatu yang tidak sesuai dengan yang seharusnya)" (Al-Lahji, n.d.: 68)

Yaitu, menjauhi diri dari melakukan perbuatan yang berbeda atau bahkan bertentangan dengan Syariat atau yang berdasarkan kebiasaan yang sesuai dengan akal sehat, dan hal itu juga berhubungan dengan persoalan etika dan akhlak.

Dilihat dari ketiga maslahah di atas, pada hakikatnya baik kelompok, Dharuriyat, Hajiyat, maupun Tahsiniyat dimaksudkan untuk memelihara atau mewujudkan kelima pokok (tujuan hukum Islam yang asasi). Hanya saja peringkat kepentingannya berbeda satu sama lain. Kebutuhan kelompok pertama dapat dikatakan sebagai kebutuhan primer, yang kalau kelima pokok tersebut diabaikan maka akan berakibat terancamnya esensi kelima pokok itu. Kabutuhan dalam kelompok kedua dapat dikatakan sebagai kebutuhan sekunder. Artinya, kalau kelima pokok dalam kelompok ini diabaikan, maka tidak mengancam esensinya melainkan akan mempersulit dan mempersempit mengancam esensi kelima pokok itu. Dengan demikian, dapat dikatakan bahwa kebutuhan dalam kelompok ketiga lebih bersifat komplementer, pelengkap (Djamil, 1995: 41).

\section{Analisis Larangan Hiburan Malam Pasca Surat Edaran Forkompimda Kab. Aceh Tamiang}

1. Kondisi Hiburan Malam Di Kec. Karang Baru Kab. Aceh Tamiang

Sebelum membahas lebih jauh tentang analisa ada baiknya kita mengetahui lebih dahulu tentang kondisi hiburan malam di Kec. Karang Baru Kab. Aceh Tamiang sebelum adanya surat edaran Bupati tersebut terdapat keyboard di malam hari yang diselenggarakan oleh warga. Diketahu di lapangan bahwa masyarakat setuju dengan pemberlakuan edaran tersebut karena kondisi masyarakat Aceh yang harus sesuai dengan nilai yang diatur dalam Syariat Islam. Jika ada Kampung yang tetap menyelenggarakan hiburan dimaksud menurutnya akan dikenakan sanksi oleh pihak Kecamatan, maka semenjak itu hiburan malam tidak terdapat lagi di Kampung Medang Ara.

Kemudian daripada itu kenyataan di lapangan dapat dilihat bahwa dengan adanya surat edaran Forkompimda tersebut yang mengatur tentang larangan hiburan malam, karena dengan begitu menurutnya akan meminimalisir terjadinya berbagai gangguan di masyarakat seperti kebisingan, keributan dan bahkan bentrok antar pemuda Kampung, sehingga kondisi yang nyaman dan kondusif di malam hari dalam wilayah Aceh Tamiang dapat terpelihara. 
2. Pelaksanaan Hiburan Malam Yang Diatur Dalam Surat Edaran Forkompimda Aceh Tamiang

Pelaksanaan larangan hiburan malam pada kenyataannya lebih mengarah kepada Keyboard dan Karaoke, pihak Satpol PP dan WH jika terdapat pelanggaran dari maklumat tersebut akan mengambil tindakan sesuai tugas dan kewenangannya melalui kegiatan patroli rutin yang dilakukan, pemberian izin hiburan malam yang dibolehkan diterbitkan oleh Dinas Syariat Islam.

Satpol PP dan WH mengawasi akan jalannya maklumat tersebut di lapangan. Hal tersebut dilakukan untuk memastikan bahwa maklumat yang dikeluarkan oleh Forkompimda tersebut dapat terealisasikan. Namun, belum adanya sanksi yang diberikan kepada para pelanggar dikarenakan surat edaran Forkompimda tersebut hanya sebatas maklumat. Perlu perbaikan lebih lanjut juga mengenai surat edaran tersebut mengingat semakin meluasnya praktik hiburan malam yang dilakukan dengan beragam model.

Pihak Dinas Syariat Islam sedang menyusun Rancangan Qanun berkaitan tentang larangan hiburan malam tersebut. Jadi, surat edaran Forkompimda tersebut menjadi titik tolak awal untuk menaikkan statusnya ke Qanun agar memiliki kekuatan hukum. Selain itu juga di beberapa Kampung dalam wilayah Aceh Tamiang sudah mengeluarkan Qanun Kampung berkaitan tentang hiburan malam yang dibolehkan dan yang dilarang. Maka dari itu perlu adanya Qanun Kabupaten yang mengatur akan hal tersebut yang nantinya mengatur dan menjangkau seluruh wilayah dalam Kab. Aceh Tamiang.

3. Analisis Perspektif Maqashid Syariah Terhadap Larangan Hiburan Malam Pasca Surat Edaran Forkompimda Kab. Aceh Tamiang

Surat edaran yang dikeluarkan oleh Forkompimda Kabupaten Aceh Tamiang sebagai maklumat bersama yang berisi tentang larangan hiburan malam dalam lingkungan wilayah Kabupaten Aceh Tamiang menjadi sebuah hal yang sangat berarti dan memiliki efek yang sangat luar biasa dalam menertibkan tatanan serta pola hidup masyarakat agar sesuai dengan tuntunan Syariat.

Hiburan malam yang sangat kentara terasa di dalam kebiasaan masyarakat yaitu keyboard.Keyboard memiliki daya tarik yang sangat tinggi yang bisa membuat setiap orang yang menyukainya tahan hingga larut malam. Hiburan keyboard yang berlangsung seperti itu tentu menjadi sebuah hal yang sangat rentan akan terjadinya pelanggaran Syariat. Berbagai aktivitas yang dilarang dalam Islam lumrah terjadi pada acara keyboard yang berlangsung hingga larut malam tersebut.

Pasca terbitnya maklumat bersama tersebut di tambah dengan rutinnya Satpol PP dan WH bersama Dinas Syariat Islam melakukan patroli rutin terhadap Kampung-Kampung yang melanggar maklumat tersebut banyak terjadi perubahan dalam segi kehidupan di malam hari khusunya di Kecamatan Karang Baru dan umumnya di seluruh penjuru Aceh Tamiang.Jika kita mengaitkan hal ini dengan Maqashid Syariah maka 
sesungguhnya Allah dalammenetapkanhukum adalah untuk kemaslahatan manusia untukkehidupan sekarang(dunia) dan akhirat secara bersamaan antara keduanya.

Tujuan Allah SWT mensyariatkan hukum-Nya adalah untuk memelihara kemaslahatan manusia, untuk menghindari mafsadat, ataupun gabungan keduanya sekaligus, baik di dunia maupun di akhirat. Dalam rangka mewujudkan kemaslahatan di dunia dan di akhirat berdasarkan penelitian paraahli Ushul Fiqh, ada lima unsur pokok yang harus di pelihara dan diwujudkan. Kelima pokok tersebut adalah agama, jiwa, akal, keturunan, dan harta. Maka dalam konteks pelarangan hiburan malam khususnya keyboard yang dilakukan oleh Forkompimda Kabupaten Aceh Tamiang ada hal yang ingin dijaga yaitu memelihara agama Islam ini agar segala bentuk Syariat yang telah Allah tetapkan dapat terwujudkan di tengah kehidupan masyarakat. Kemudian memelihara akal agar tidak dirusak dengan hal-hal yang negatif seperti pengaruh minuman keras, ganja, sabu-sabu dan lain sebagainya yang dapat merusak sistem kerja otak yang berakibat pada hilangnya akal sehat dalam tindakan. Kemudian juga memelihara keturunan agar tidak terjadi perzinaan dalam keberlangsungan keyboard dimaksud terlebih jika telah sampai larut malam.

Dalam Alquran surah al-Maidah ayat 48, Allah SWT berfirman:

"Dan Kami telah turunkan kepadamu Al-Quran dengan membawa kebenaran, membenarkan apa yang sebelumnya, yaitu Kitab-Kitab (yang diturunkan sebelumnya) dan batu ujian terhadap Kitab-Kitab yang lain itu; Maka putuskanlah perkara mereka menurut apa yang Allah turunkan dan janganlah kamu mengikuti hawa nafsu mereka dengan meninggalkan kebenaran yang telah datang kepadamu. Untuk tiap-tiap umat diantara kamu, Kami berikan aturan dan jalan yang terang. Sekiranya Allah menghendaki, niscaya kamu dijadikan-Nya satu umat (saja), tetapi Allah hendak menguji kamu terhadap pemberian-Nya kepadamu, Maka berlomba-lombalah berbuat kebajikan. hanya kepada Allah-lah kembali kamu semuanya, lalu diberitahukan-Nya kepadamu apa yang telah kamu perselisihkan itu, (Q.S. Al-Maidah: 48)

Dalam tafsir Muyassar dijelaskan maksud ayat diatas yakni Kami telah memuliakan mu, hai Muhammad, dengan menurunkan kepadamu Alquran yang membawa ajaran yang benar, dan memisahkan antara kesesatan dan petunjuk. Kitab ini membenarkan kitab-kitab yang terdahulu, seperti taurat dan injil, menetapkan kebenaran yang ada di dalamnya dan menolak penyimpangan yang disusupkan di dalamnya.

Alquran menghapus sebagian besar hukum yang di dalamnya terdapat kesulitan, beban dan belenggu. Engkau, hai Muhammad SAW, harus memutuskan semua perkara berdasarkan pada apa yang telah diturunkan oleh Allah SWT didalam kitabNya dan sunah yang suci. Jangan sekali-kali engkau bertindak mengikuti keinginan dan hawa nafsu manusia, dan meninggalkan wahyu.Tetapi, ikutilah kebenaran.Biarlah senang orang yang ridha dan biarlah benci orang yang tidak suka. 
Syariat memang berbeda.Namun, dasar agama tetap satu, yaitu Islam.Umat yahudi memiliki Syariat yang terperinci dalam hukum-hukum yang dikhususkan untuk mereka. Begitu pula umat kristen dan umat Islam (Al-Qarni, 2007: 551-552). Setelah Allah Ta'ala menuturkan Taurat, memujinya, dan menyuruh supaya mengikutinya dan menceritakan Injil, memujinya, dan menyuruh pemeluknya supaya mengamalkan isinya, maka kini dia mulai menceritakan Alquran yang mulia yang diturunkan kepada hamba dan RasulNya yang mulia, Muhammad SAW. Allah berfirman, "Dan kami telah menurunkan kepadamu Alquran dengan membawa kebenaran, "yakni dengan membawa kebenaran yang tidak diragukan lagi bahwa ia benar-benar dari sisi Allah. "Yang membenarkan Kitab-Kitab sebelumnya", yakni kitab-kitab terdahulu yang mengandung cerita dan pujian serta berita akan diturunkannya sebuah kitab dari sisi Allah kepada hamba dan Rasulnya, Muhammad SAW. Maka turunnya Alquran, sebagaimana diinformasikan oleh kitab-kitab terdahulu, merupakan perkara yang menambah kebenaran para pembawanya, yaitu kaum yang berpandangan mata dan hati, yang menurut kepada berbagai perintah Allah, mengikuti aneka SyariatNya, membenarkan ucapan para RasulNya, yang menjanjikan akan datangnya Muhammad SAW secara pasti. Dan, dia memang benar-benar datang (ArRifa'i, 1991: 104).

Berdasarkan penafsiran diatas, bahwa sanya Allah SWT telah menurunkan Alquran sebagai kitab yang sempurna dan menyempurnai kitabkitab terdahulu.Alquran juga diturunkan sebagai pedoman bagi umat Islam untuk melihat suatu hukum dari sebuah kejadian.Serta Allah SWT memerintahkan Rasulullah untuk memutuskan sebuah perkara denganapa yang Allah turunkan (Alquran) bukan dengan mengikuti hawa nafsu.Dalam hal ini jelas bahwa sanya hukum yang Allah turunkan kepada manusia menghendaki kemaslahatan bagi setiap manusia.Bukan berdasarkan kepentingan individu saja melainkan mencakup keseluruhan.

Seperti halnya mengenai terbitnya surat edaran Forkompimda Aceh Tamiang yang memberikan konsekuensi hukum bagi yang melanggar ketentuan dalam surat edaran tersebut. Menunjukkan bahwa surat edaran Fokompimda di peruntukan bagi kemaslahatan setiap orang atau masyarakat di Aceh Tamiang demi menjauhkan dari setiap keburukan yang dapat mengancam Agama, Akal dan keturunan.

\section{Penutup}

Berdasarkan hasil kajian yang penulis lakukan dan didukung dengan teori-teori yang dijadikan landasan berfikir dalam memahami permasalahanpermasalahan, disertai paparan yang telah penulis kemukakan dalam kajian ini, maka dapatlah penulis simpulkan sebagai berikut: Keadaan Kecamatan Karang Baru Kabupaten Aceh Tamiang sebelum adanya surat edaran Bupati tersebut terdapat keyboard di malam hari yang diselenggarakan oleh warga. Namun, setelah adanya Surat Edaran Forkompimda tersebut hiburan keyboard sudah tidak dilaksanakan hingga larut malam lagi. Hiburan 
tersebut dibatasi hanya sampai pukul 18.00 wib. Surat edaran Forkompimda yang mengatur tentang larangan hiburan malam dalam wilayah Kabupaten Aceh Tamiang berisi tentang dilarangnya mengadakan hiburan seperti keyboard pada malam hari. Namun, di dalam surat edaran tersebut belum adanya sanksi yang diberikan kepada para pelanggar dikarenakan Surat Edaran Forkompimda tersebut hanya sebatas maklumat. Perlu perbaikan lebih lanjut juga mengenai Surat Edaran tersebut.

Tujuan pelarangan hiburan malam khususnya keyboard yang dilakukan oleh Forkompimda Kabupaten Aceh Tamiang ada hal yang ingin dijaga yaitu memelihara agama Islam ini agar segala bentuk Syariat yang telah Allah tetapkan dapat terwujudkan di tengah kehidupan masyarakat. Kemudian memelihara akal agar tidak dirusak dengan hal-hal yang negatif seperti pengaruh minuman keras, ganja, sabu-sabu dan lain sebagainya. Kemudian juga memelihara keturunan agar tidak terjadi perzinaan dalam keberlangsungan keyboard dimaksud terlebih jika telah sampai larut malam. 


\section{Daftar Pustaka}

Al-Lahji, A.-S. A. ibn S. M. 'Abbadi. (n.d.). Idhah al-Qawa'id al-Fiqhiyyah (Terjemahan). Jeddah: al-Haramain.

Al-Qarni, A. (2007). Tafsir Muyassar. ( terj. T. Q. Press, Ed.). Jakarta: Qisthi Press.

Al-Qur'an dan Terjemahannya. (n.d.) (hal. 439). Jakarta: Departemen Agama Republik Indonesia.

al-Rahman, Imam Jalal al-Din Abd, ibn A. B. al-S. (n.d.). al-Asybah waalNazha'ir fi al-Furu' (Terjemahan). Semarang: Maktabah wa Mathba'ah Thaha Putra.

Al Ashbahani, A. N. A. (2004). Hilyatu Al Awliya' Wa Thabaqatu Al Ashfiya'. (D. Terj: Abdullah Al Misyawi, Ed.) (Jilid 6). Jakarta: Pustaka Azzam.

Ar-Rifa'i, M. N. (1991). Ringkasan Tafsir Ibnu Katsir. Jakarta: Gema Insani.

Badan Pusat Statistik Aceh Tamiang. (2018). Aceh Tamiang.

Djamil, F. (1995). Metode Ijtihad Majlis Tarjih Muhammadiyah. Jakarta: Logos.

Efendi, S. (2008). Ushul Fiqh. Jakarta: Kencana.

Ibn Zakariyya, A. al-H. A. ibn F. (1994). Mu'jam al-Muqayyis fi al-Lughah. Beirut: Dar al-Fikr.

Mukhibad, H. (2019). The Role of Sharia Supervisory Boards in Meeting Maqasid Syariah-Study on Islamic Banks in Indonesia. European Journal of Islamic Finance, 13(13), 1-9. https://doi.org/10.13135/2421-2172/3620

Musolli, M. (2018). Maqasid Syariah: Kajian Teoritis dan Aplikatif Pada Isu-Isu Kontemporer. AT-TURAS: Jurnal Studi Keislaman, 5(1), 60-81. https://doi.org/10.33650/at-turas.v5i1.324

Muzlifah, E. (2013). Maqasyid Syariah Sebagai Paradigma Dasar Ekonomi Islam. Istislah: Jurnal Ekonomi dan Hukum Islam, 3(2), 79.

Qanun Kabupaten Aceh Tamiang Nomor 11 Tahun 2008 tentang Izin dan Tata Cara Penyelenggaraan Hiburan, Pub. L. No. Nomor 11 Tahun 2008 (2008). Indonesia.

Rahmi, N. (2018). Maqasid Al Syari'ah: Melacak Gagasan Awal. Syariah Jurnal Hukum dan Pemikiran, 17(2), 160. https://doi.org/10.18592/sy.v17i2.1970

Selebaran Surat Edaran yang dikeluarkan di Karang Baru. (2015). Aceh Tamiang.

Wira, A. (2001). Metode Ijtihad Yusuf Qardhawi (Cetakan ke). Jakarta: Nuansa Madani. 